\title{
ESCENARIOS CULPOSOS EN LA INVESTIGACIÓN
}

\author{
FAULTY SCENARIOS IN THE INVESTIGATION \\ (iD) Edgar Gutiérrez Gómez ${ }^{*}$ \\ egutierrez@unah.edu.pe \\ ${ }^{1}$ Universidad Nacional Autónoma de Huanta, Ayacucho, Perú
}

\begin{abstract}
*Correspondencia: Edgar Gutiérrez Gómez. Email: egutierrez@unah.edu.pe
\end{abstract}
El fenómeno actual que vive la humanidad, conlleva virar seriamente al escenario de la investigación científica. Aspecto fundamental que genera alternativas de solución a los avatares de la naturaleza que afrontamos en la convivencia humana. La investigación en el Perú y en otras partes del mundo, fue rezagada por situaciones suntuarias de lo efímero de la satisfacción inmediata. Las consecuencias para afrontar las epidemias y problemas sociales se evidencian en la salud pública y el caos social que se genera a falta de alternativas de investigación social.

La falta de inversión en la ciencia, traerá consigo deficiencias en la atención inmediata a fenómenos adversos al hombre y con independencia a su voluntad. El Perú es uno de los países que menos invierte en la investigación científica: "En esa línea, sostuvo que, si bien el Perú ha quintuplicado su inversión en la ciencia y tecnología en los últimos diez años, aún es poco en comparación con los países de la región” (Gestión, 2020). Así declaró Fabiola León-Velarde presidenta de CONCYTEC. El avance en la investigación es en conjunto con la inversión económica, los investigadores en el Perú realizan su función en condiciones inadecuadas sin atención preferencial.

Las universidades peruanas con sus profesionales en diferentes áreas que generan profesionales para el mercado, tienen limitaciones en su quehacer investigativo. Al margen de las quejas convalecientes de sentirse contemplativos y que no suma al entusiasmo científico, la Universidad Nacional Autónoma de Huanta-Ayacucho, hace una entrega de su trabajo en investigación. Nos reafirmamos: “... seguir bregando dentro de la academia de la intelectualidad, dejando de lado los intereses mezquinos de exigir al Estado; sin esmerarse en contribuir en lo mínimo a lo invertido en la ciencia, lo cual, la ética de la investigación cuestiona" (Gutiérrez, 2020, p.76). Esta vez hacemos la entrega de diferentes profesionales que colaboraron con sus trabajos de investigación. Nuestra línea de investigación es multidisciplinar que permite el pluralismo de contenidos que entregamos al usuario.

Algunas personas, incluyendo políticos de turno, aprovechan la coyuntura para figurar en el escenario de la pandemia. Generan más caos, asumiendo una situación de culpa, al no haber generado políticas de inversión en salud y asuntos públicos. Autoflagelarse en escenarios caóticos es restar la solución a un problema. Es tiempo que las entidades privadas financien la investigación en diferentes áreas del saber humano. Sería una forma de retribuir a los dividendos que hayan generado en su actividad económica en situaciones de aparente normalidad.

La entrega de este volumen y número, conlleva el entusiasmo y compromiso de seguir trabajando en la sostenibilidad de nuestro trabajo científico. Tuvimos acogida en 
nuestra convocatoria, pues numerosos colaboradores científicos, ansiaron publicar su investigación en nuestra revista. A ellos nuestra gratitud por seguir apostando en la academia y, no rezagarse como los culposos que no aportaron a la humanidad. Existe un camino no allanado para seguir en la investigación, liberándose de las taras culposas de lo acaecido para multiplicar la producción en la investigación: "De modo que resulta insuficiente afirmar: olvidémonos del escritor, olvidémonos del autor, y vamos a estudiar, en sí misma, la obra. La palabra 'obra' y la unidad que designa probablemente son tan problemáticas como la individualidad del autor" (Foucault, 1970, p.10). La investigación culposa en la actualidad que se vincula más a la salud, que no deje de lado la investigación social, que es lo más importante para comportarse de manera disciplinada. Las especulaciones humanas de la ciencia, conllevan al ostracismo de la pseudociencia que invade a la desesperación del hombre por conservar la vida.

\section{REFERENCIAS BIBLIOGRÁFICAS}

Foucault, M. (1970). ¿Qué es un Autor? Littoral, 47.

Gestión, R. (2020). S / 16 millones se han sido invertido en la comunidad científica durante el estado de emergencia. Gestión.

Gutiérrez, E. (2020). La eticidad en el proceso de la investigación. Puriq, 75-77.

\section{CITAR COMO:}

Gutiérrez Gómez, E. (2020). Escenarios culposos en la investigación. Puriq, 2(3), 139-140. https://doi.org/10.37073/puriq.2.3.110 